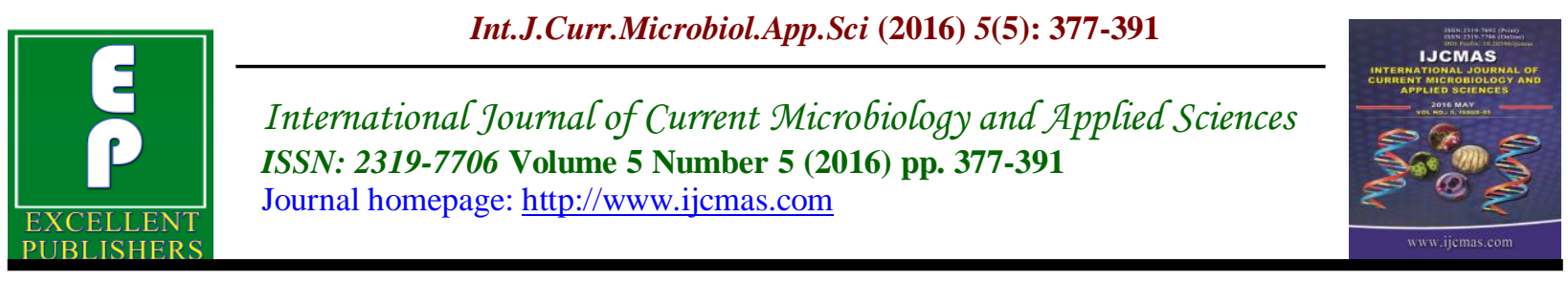

Review Article

http://dx.doi.org/10.20546/ijcmas.2016.505.039

\title{
Endophytes: The Producers of Important Functional Metabolites
}

\author{
Suriya Rehman* \\ Department of Biology, College of Science, University of Dammam, KSA \\ *Corresponding author
}

\begin{abstract}
A B S T R A C T
Keywords

Natural product based compounds have immense impact on modern medicine.

Endophytes, Pharmaceutical, Metabolites, Ecosystem.

Article Info More than $50 \%$ of the new chemical products registered with FDA during 19812002 as anti-cancer agents, anti-migraine agents and anti-hypertensive agents were with natural products or derived thereof. Some possible sources of natural products include mostly plants, which are extensively being used by man and may lead to their permanent loss from habitat. This natural loss is important to the society for a number of reasons, including the maintenance of ecosystem, functioning and for ethical reasons and specifically important to pharmaceutical companies in their search for novel natural products. Amongst the plants being lost, will be some Accepted: 15 April 2016 Available Online: 10 May 2016 which have the ability to produce important, but as yet undiscovered bioactive molecules. Though efforts are on to conserve these important species involving insitu and exsitu cultivation and the search for microbial diversity associated with the plants known as endophytes. Endophytes are microorganisms (bacteria or fungi or actinomycetes) that dwell within robust plant tissues by having a symbiotic association. A large amount of bioactive compounds produced by them not only are
\end{abstract}

\section{Introduction}

From 1981-2002, only $43 \%$ of the drugs were purely synthetic, while remaining $57 \%$ were derived from natural source (Newman et al., 2003). Out of 250,000 (approx.) higher species of plants, it is estimated that only $5-15 \%$ has been investigated for natural products (Cragg and Newman, 2001a).

The world Health Organization (WHO) estimates that approximately $80 \%$ of the world relies on natural sources directly or indirectly for primary medicinal treatment and that the health care systems for the remaining $20 \%$ of the population also incorporate natural sources in their medicinal treatment (Cragg, 2002).
Also research suggests that less than $1 \%$ of bacterial species and less than $5 \%$ of fungal diversity are currently known (Cragg and Newman, 2001b). Microorganisms known as endophytes colonizing inside plant tissues usually get nutrition and protection from the host plant and in return, they confer profoundly enhanced fitness to the host plants by producing certain functional metabolites. In addition, fungal endophytic metabolites are useful resources for natural products which effectively have wide range of application in medicine, agriculture, and industry (Selim et al., 2012). Endophytes have been recognized as a repository of novel metabolites of pharmaceutical 
importance (Tan and Zou, 2001). Many endophytes of the same species are isolated from the same plant and only one of the endophyte will produce a highly active compound in culture (Li, et al., 1996). The reason why some endophytes produce certain phytochemicals originally characteristic of the host might be related to a genetic recombination of the endophyte with the host (Tan and Zou, 2001). This is a concept that was originally proposed as a mechanism to explain why the endophytic fungus $T$. andreanae may be producing paclitaxel (Stierle et al., 1993). Thus, if endophytes can produce the same rare and important bioactive compounds as their host plants, this would not only reduce the need to harvest slow-growing and possibly rare plants but also preserve the world's diminishing biodiversity.

\section{Here is the List of Natural Functional Metabolites Produced by Endophytic Microbes and their Potential in the Pharmaceutical and Agrochemical Arenas.}

\section{Antimicrobial Compounds}

Natural products from endophytic microbes have been observed to inhibit or kill a wide variety of harmful disease causing agents including, bacteria fungi, viruses and protozoans that affect humans and animals. There are number of antimicrobial compounds primarily known from plants, have now being reported as metabolites of endophytic fungi, such as coumarin found in extracts of strains of Alternaria spp., Penicillium spp and Aspergillus flavus from the annual herb Crotalaria pallida (Umashankar et al., 2014), a strain of Fusarium chlamydosporum from stem of Tylophora indica (Asclepiadaceae) producing kaempferol (Chaturvedi et al., 2014).
Cryptocin, a unique tetrameric acid is produced by Cryptosporiopsis quercina. This unusual compound possesses potent activity against Pyricularia oryzae as well as a number of other plant-pathogenic fungi. $C$. quercina also demonstrated excellent antifungal activity against some important human fungal pathogens like Candida albicans and Trichophyton sp (Li et al., 2000). A unique peptide antimycotic, termed cryptocandin, was isolated and characterized from $C$. quercina, the bioactive compound is related to the known antimycotics, the echinocandins and the pneumocandins. As is generally true not one but several bioactive and related compounds are produced by a microbe. Thus, other antifungal agents related to cryptocandin are also produced by C. quercina. Cryptocandin is also active against a number of plant-pathogenic fungi including Sclerotinia sclerotiorum and Botrytis cinerea. Cryptocandin and its related compounds are currently being considered for use against a number of fungi causing diseases of skin and nails (Walsh, 1992).

The ecomycins are produced by Pseudomonas viridifolia, which is generally associated with leaves of many grass species and is located within the tissues. The ecomycins are active against such humanpathogenic fungi as Cryptococcus neoformans and C. albicans (Miller, 1998).

Another group of antifungal compounds is the pseudomycins, produced by a plantassociated pseudomonad. The pseudomycins represent a family of lipopeptides that are active against a variety of plant and humanpathogenic fungi (Harrison et al., 1991, Ballio et al., 1994). The molecules are candidates for use in human medicine especially after structural modification has successfully removed mammalian toxicity (Zhang et al., 2001). 
A strain of Pestallotiopsis microspora was also isolated from the endangered tree Torreya taxifolia which produces several compounds that have antifungal activity, including pestaloside, an aromatic $\beta$ glucoside, and two pyrones; pestalopyrone and hydroxypestalopyrone, caryophyllene sesquiterpenes, pestalotiopsins A and B, 2hydroxydimeninol (Lee et al., 1995a, Pulici et al., 1996b, 1996c, 1997).

Also Capitulatin B, hydroxycapitulatin B, antimicrobial compounds have been obtained from Nigrospora oryzae of Aquilaria sinensis ( $\mathrm{Li}$ et al., 2014), Isocaryophyllene from Muscodor sutura of Prestonia trifidi (Kudilkar et al., 2012), Arundinols, arundinones from Microsphaeropsis arundinis of Ulmus macrocarpa (Luo et al., 2014), Bisabolol from Muscodor kashayum of Aegle marmelos (Meshran et al., 2013).

Pestalotiopsis microspora is a common rainforest endophyte (Strobel, 2002a). It turns out that enormous biochemical diversity does exist in this endophytic fungus, and as such there seem to be many secondary metabolites produced by this widely dispersed fungus. One such secondary metabolite is ambuic acid, an antifungal agent which has been recently described from several isolates of Pestalotiopsis microspora (Li et al., 2001). Species of Pestalotiopsis namely Pestalotiopsis jesteri from the Sepik River area of Papua New Guinea, produces jesterone and hydroxy-jesterone, which exhibit antifungal activity against a variety of plant-pathogenic fungi ( $\mathrm{Li}$ and Strobel, 2001).

An endophytic Fusarium sp. from the plant Selaginella pallescens, collected in the Guanacaste, conservation Area of Costa Rica, was screened for antifungal activity. A new antifungal agent, CR377, was isolated from the culture broth of the fungus that showed potent activity against $C$. albicans (Brady and Clady, 2000).

Phomopsichalasin, a metabolite from an endophytic Phomopsis spp mainly exhibit antibacterial activity against Bacillus subtilis and Staphylococcus aureus. It also displays a moderate activity against the yeast Candida tropicalis (Horn et al., 1995).

Colletotric acid is a metabolite of an endophyte, Colletotrichum gloeosporiodes isolated from Artemisia annua, a traditional Chinese herb that is well recognized for its synthesis of artemisinin (an anti-malarial drug). The Colletotrichum sp, found in A. annua produced not only metabolites with activity against human- pathogenic fungi and bacteria but also metabolites that were fungistatic to plant-pathogenic fungi ( $\mathrm{Lu}$ et al., 2000).

Antibiotics called munumbicins produced by Streptomyees sp posses widely differing biological activities, depending on the target organism. In general, the munumbicins demonstrate activity against gram-positive bacteria such as Bacillus anthracis and multidrug-resistant $M$. tuberculosis as well as a number of other drug resistant bacteria (Castillo et al., 2002).

Another endophytic streptomycete (NRRL 30566) from a fern-leaved Grevillea tree (Grevillea pteridifolia) growing in the Northern Territory of Australia produces in culture novel antibiotics called kakadumycins (Castillo et al., 2003). Two active ingredients identified as (i) 5, 7dimethoxy-4-p-methoxyphenyl coumarin and (ii) 5, 7-dimethoxy-4-p-phenyl coumarin from endophytic Streptomyces aureofaciens isolated from root tissue of Zingiber officinale showed antifungal activity against Colletotrichum musae and Fusarium oxysporum (Tacchowisan et al., 2005). 
Muscudor albus is an endophytic fungus obtained from small limbs of Cinnamomum zeylanicum (cinnamon tree). This xylariaceaous (non-spore-producing) fungus effectively inhibits and kills certain other fungi and bacteria by producing a mixture of volatile compounds. The ecological implications and potential practical benefits of the "mycofumigation" effects of M. albus are very promising, given the fact that soil fumigation utilizing methyl bromide will soon be illegal in the United States. This organism is already in the market for the decontamination of human wastes. Muscodor roseus obtained from the tree species growing in the Northern Territory of Australia is effective in causing inhibition and death of test microbes in the laboratory as M. albus (Worapong et al., 2002).

In addition for the first time, a non muscodor species, Gliocladium spp was discovered to be a volatile antibiotic producer. The volatile components of this organism are totally different from those of either M. albus or M. roseus. In fact, the most abundant volatile inhibitor is annulene formerly used as a rocket fuel and discovered for the first time as a natural product in an endophytic fungus (Stinson and Strobel, 2003).

Another fascinating use of antibiotics products from endophytic fungi is the inhibition of viruses, two novel human cytomegalovirus protease inhibitors, cytonic acids A and B have been isolated from the solid-state fermentation of the endophytic fungus, Cytanaema sp. It is apparent that the potential for the discovery of compounds from endophytes, having antiviral activity is in its earliest. The main limitation for the discovery of antiviral compounds from endophytes is probably related to the absence of appropriate antiviral assay systems (Guo et al., 2000).
Two compounds, pestacin and isopestacin have been obtained from culture fluids of Pestalotiopsis microspora, an endophyte isolated from a combretaceaous plant, Terminalla morobensis growing in the Sepik River drainage of Papua New Guinea. Both pestacin and isopestacin display antimicrobial as well as antioxidant activity (Harper et al., 2003).

Moreover, production of saponins has been recently documented for strains of $A$. alternata, A. niger and Penicillium sp. from Loranthus sp. (Govindappa et al., 2011), dihydrocumambrin A, known as a secondary metabolite of Glebionis coronaria (Chrysanthemum coronarium), has been recently extracted as a fermentation product of a strain of Lasiodiplodia (=Botryodiplodia) theobromae endophytic in leaves of Dracaena draco [Zaher et al., 2015], all possessing the antimicrobial properties.

\section{Anticancer Compounds}

Numerous reviews have highlighted the importance of compounds derived from microbial sources in treating human diseases. In addition to the anti-infective area, natural products have also had a major impact on cancer therapy. Surveying the period from 1981 to 2002, Newman et al., reported that $>60 \%$ of the approved drugs for cancer treatments are natural products or derivatives of natural products. The search for natural products as potential anticancer agents dates back to $1550 \mathrm{BC}$, but the scientific period of this search is much more recent. Much of nature remains unexplored, particularly the marine and microbial environments, and the interplay of these two sources, as exemplified by review of Colwell 2002, leaves no doubt that a host of novel bioactive chemotypes awaits discovery. A large number of plants, marine 
and microbial sources have been tested as leads and many compounds have survived the potential leads. Several potential lead molecules such as camptothecin, vincristine vinblastine, taxol, podophyllotoxin, combretastatins, etc. have been isolated from plant and many of them have been modified to improve activity and reduce toxicity. Several successful molecules like topotecan, irinotecan, taxotere, etoposide, teniposide, etc. have emerged as drugs upon modification of these natural leads and many more are yet to come.

The alkaloids are also commonly found in endophytic fungi. Fungal genera like Xylaria, Phoma, Hypoxylon, and Chalara sps are representative producers of a relatively large group of substances known as the cytochalasins of which over 20 are now known. Many of these compounds possess antitumor and antibiotic activities. Three novel cytochalasins have recently been reported from a Rhinocladella sp. as an endophyte on Tripterygium wilfordii. These compounds have antitumor activity (Wagenaar et al., 2000).

The presence of paclitaxel, a highly functionalized diterpenoid in each of the world's yew (Taxus) species prompted the study of their endophytes (Suffness, 1995). The mode of action of paclitaxel is to preclude tubulin molecules from depolymerizing during the process of cell division. This compound is the world's first billion-dollar anticancer drug. It is used to treat a number of other human tissueproliferating diseases as well. After several years of effort, a novel paclitaxel-producing endophytic fungus $T$. andreanae was discovered in $T$. brevifolia (Schiff and Horowitz, 1980, Strobel et al., 1993), Acremonium sp from Taxus globose (Soca et al., 2011, Kusari et al., 2014b), Fusarium proliferatum (Xiong et al 2013),
Fusarium redolens from Taxus wallichiana (Garyali et al., 2013. Other investigators have also made observations on paclitaxel production by endophytes, including the discovery of paclitaxel production by a Tubercularia sp. isolated from southern Chinese yew (Taxus mairel) (Wang et al., 2000). Three endophytes of $T$. wallichiana produce paclitaxel, including Sporormia minima and a Trichothecium sp. By the use of high-performance liquid chromatography and electrospray mass spectroscopy, paclitaxel has been discovered in Corylus avellana. Several fungal endophytes of filbert produce paclitaxel in culture. One of the most commonly isolated endophytic species is $P$. microspore (Stroble 2002a). An examination of the endophytes of Taxus wallichiana yielded Pestalotiopsis microspore and a preliminary monoclonal antibody test indicated that it might produce paclitaxel. Several other Pestalotiopsis isolates were obtained from bald cypress in South Carolina and also shown to produce paclitaxel. This was the first indication that endophytes residing in plants other than Taxus sp. were producing paclitaxel. Simply it appears that the distribution of the fungi making paclitaxel is worldwide and not confined to yew. From the extremely rare and previously thought to be extinct, Wollemi pine (Woliemia nobilis), Pestalotiopsis was isolated, which was shown to produce paclitaxel (Strobel et al., 1997). Also quite surprisingly, a rubiaceous plant, Maguireothamnus speciosus, yielded a novel fungus, Seimatoantlerium tepuiense that produces paclitaxel. Furthermore fungal paclitaxel production has also been noted in Periconia sp. and in Seimatoantlerium nepalense another novel endophytic fungal species (Bashyal et al., 1999). However that paclitaxel production by all endophytes in culture is in the range of submicrograms to micrograms per litre. Also commonly endophytic fungi will attenuate paclitaxel 
production in culture. However, it is possible to recover paclitaxel production in attenuated cultures if certain activator compounds are added to the medium ( $\mathrm{Li}$ et al., 1998).

Torreyanic acid, a selectively cytotoxic quinine dimmer (anticancer agent) was isolated from a Pestalotiopsis microspora strain. This strain was originally obtained as an endophyte associated with the endangered tree $T$. taxifolia (Florida torreya) (Li et al., 2002).

The extract of a Curvularia sp. an endophytic fungus isolated from Ocotea corymbosa showed moderate antifungal activity against Cladosporium sphaerospermum and C. cladosporioides. Further studies of crude ethyl acetate extract afforded two new benzopyran derivatives and two known compounds which caused a potent stimulus to two mammalian cell lines. Recently fractionation of the extract of Aspergillus niger, an endophyte in Cyndom dacivion gave four known compounds rubrofusarin $\mathrm{B}$, Biosecinone $\mathrm{A}$, asperpytone $\mathrm{B}$ and auasperone $\mathrm{A}$ which were further investigated for bioactivity and it was observed to be cytotoxic to the colon cancer cell line (Teles et al., 2005).

Camptothecin, an anticancer drug molecule have also been isolated from endophytic fungi like Entrospora infrequens and Neuospora crassa idolated from Nothapodytes foetida, an important medicinal herb (Puri et al., 2005b, Rehman. et al., 2008). Furthermore, CPT production by a strain of $F$. solani from $C$. acuminata was even notably increased by supplying an ethanolic extract of leaves of $C$. roseus containing strictosidine as a precursor in CPT biosynthesis, and even by ethanol itself (Venugopalan and Srivastava, 2015).
Podophyllotoxin has been discovered from various Podophyllum plant species. The production of bioactive lignans by novel fungal endophytes Trametes hirsua and Fusarium oxysporum which exhibit potent antioxidant, anticancer and radioprotective properties have also been reported (Porter and Eyberger, 2004, Puri et al., 2005a, Amardeep et al., 2007).

\section{Immunoregulators}

The endophytic fungus Fusarium subglutinans isolated from $T$. wilfordii produces the non toxic immunosuppressant diterpene pyrones, subglutinol $\mathrm{A}$ and $\mathrm{B}$. Immunosuppressive drugs are used today to prevent allograft rejection in transplant patients and in future they could be used to treat autoimmune diseases such as rheumatoid arthritis and insulin-dependent diabetes (Lee et al., 1995b).

Pestalotiopsis species have been reported to secrete immunosuppressive compounds in culture broth. Pestalotiopsis sp., isolated as an endophytic fungus from $T$. brevifolia (Yew tree) produces immunosuppressive pestalotiopsins A and B in liquid culture (Pulici et.al., 1996a). Pestalotia sp, isolated from a pea plant (Cassia fistula), produces immunosuppressive, cytochalasin (Burres et al., 1992). Pestalotiopsis leucothes, an endophytic fungus from $T$. wilfordii has tremendous immunomodulatory effects especially suppression of various activities of peripheral blood mononuclear cells. Bioassay guided purification of the crude extracts of $P$. leucothes revealed three compounds that accounted for its activity (Kumar et al., 2003, 2005).

The Microbiology Department at Sandoz Ltd. developed a computer-aided evaluation program to screen and evaluate fungi for bioactivity. This approach resulted in the 
discovery of the fungus Tolypocladium inflatum, from which cyctosporine, a hugely beneficial immunosuppressant was isolated (Borel and Kis, 1991).

Caffeine, the methylxanthine alkaloid from Coffea sp. well known as a psychoactive drug, has been evidenced in extracts of unidentified endophytic fungi recovered from the Indian ethnomedicinal plants Osbeckia chinensis, $O$. stellata and Potentilla fulgens (Bhagobaty et al., 2011). Piperine is an alkaloid of Piper longum and Piper nigrum known for its immunoregulatory and antitumor properties and this valuable compound has been extracted from liquid cultures of endophytic strains of Periconia sp. From P. longum (Verma et al., 2011), and Mycosphaerella sp (Chithra et al., 2014a) and $C$. gloeosporioides from $P$. nigrum (Chithra et al., 2014b).

\section{Antidiabetic Compounds}

A nonpeptidal fungal metabolite (L-783, 281) was isolated from an endophytic fungus (Pseudomassaria sp.) collected from an African rainforest. This compound acts as insulin mimetic and unlike insulin is not destroyed in the digestive tract and may be given orally. Oral administration of L-783, 281 to two mouse models of diabetes resulted in significant lowering of blood glucose level (Zhang et al., 1999). Berberine is a cardioprotective and antidiabetic product known from several unrelated medicinal plants (Sun etal 2009), which has been recently found as a secondary metabolite of a strain of $F$. solani from roots of the medicinal liana Coscinium fenestratum (Vinodhini et al., 2013).

\section{Anti-insect Compounds}

As the world becomes wary of ecological damage done by synthetic insecticides, endophytic research continues for the discovery of powerful, selective and safe alternatives. Several endophytes are known to have anti-insect property. Nodulisporic acids, novel indole diterpenes exhibit potent insecticidal properties against the blow fly. The first Nodulisporic compounds were isolated from an endophyte, a Nodulisportum sp. from the plant Bontia daphnoides (Demain, 2000). Insect toxins have also been isolated from an unidentified endophytic fungus from wintergreen (Gaultheria procumbens). The two new compounds, 5-hydroxy-2-p-hydroxy-5'methyl-4'-hexenyl benzofuran and 5hydroxy-2-(P-oxo-5'-methyl-4'-hexenyl benzofuran both show toxicity to spruce budworm (Findlay et al., 1997). Another endophytic fungus, Muscodor vitigenus, isolated from a Paullina paullinioides yields naphthalene as its major product. Naphthalene, the active ingredient in common mothballs is a widely exploited insect repellant. $M$. vitigenus shows promising preliminary results as an insect deterrent and exhibits potent insect repellency against the wheat stem sawfly (Cephus cinctus) (Daisy et al., 2002a, 2002b). Terpenes from Copaifera demonstrated in vitro antiparasitic and synergic activity (Izumi et al., 2012). Azadirachtins A and B have been recently extracted from cultures of a strain of Penicillium (Eupenicillium) parvum endophytic in the neem plant (Azadirachta indica) possessing insecticidal activity (Kasuri et al., 2014a).

Plant hormones are undoubtedly among the main secondary metabolites that can influence plant fitness and enhance development when exogenously administered. Many fungal species have been reported to be able to produce compounds such as indole-3-acetic acid (IAA) and gibberellins (GAs), particularly 
species inhabiting rhizosphere which are presumed to exert a consistent effect on plant development (Manici et al., 2015). The interaction of crop plants with endophytic fungi producing gibberellins could be exploited as a strategy to overcome the adverse effects of abiotic stresses, considering the increased plant growth and biomass production that have been documented even in extreme environmental conditions (Khan et al., 2015).

Production of IAA by fungi establishing a mutualistic relationship with plants was first evidenced by a few mycorrhizal species recovered from pine and orchid roots (Ek and Ljungquid 1983). Afterwards it has been reported by strains of Colletotrichum sp. from Artemisia annua (Lu et al., 2000), Talaromyces verruculosus (=Penicillium verruculosum) from roots of Potentilla fulgens (Bhagobaty et al 2009), and Penicillium glabrum from pomegranate (Punica granatum) fruits ( Hammerschmidt et al., 2012). IAA is also produced by Piriformospora indica ( Sirrenberg et al., 2007), the quite famous Basidiomycetes species and later found to be widespread and able to colonize roots of many host plants, disclosing a potential for applications in crop production [Qiangetal et al., 2012).

Other endophytic fungi have been found to produce both IAA and GAs, such as two strains of Fusarium sp. from Euphorbia pekinensis Dai and $\mathrm{Yu}, 2008)]$. Moreover, a strain of Galactomyces geotrichum isolated from the aquatic plant Trapa japonica produced IAA and biologically active GAs (GA1, GA4, and GA7) ( Waqas et al., 2014), while two strains from cucumber roots (Phoma glomerata and Penicillium sp.) were found to produce gibberellic acid (GA3) along with GA1, GA4, GA7, and IAA (Waqas et al., 2012), Similar effects resulted in the evaluation of another cucumber endophytic strain (Paecilomyces formosus) by the same research group (Khan et al., 2012).

The production of IAA, GA, abscisic acid and jasmonic acid in several combinations was observed by a pool of unidentified endophytic fungi recovered from five plants used in Indian ethnomedicine, Camellia caduca, Osbeckia chinensis, Osbeckia stellata,Potentilla fulgens, and Schima khasiana (Bhagobaty and Joshi, 2011).

Enzymes: Very few microorganisms living in plants, e.g., the ericoid mycorrhizal fungus Hymenoscyphus ericae were reported to be xylenase producers (Burke and Cairney, 1997). Manabu et al., (2002) isolated one hundred and sixty-nine endophytic fungi and eighty one endophytic bacteria from 14 plants in total. Among them, 155 fungi $(91.7 \%)$ and 52 bacteria $(64 \%)$ were found to produce xylenase. Like other microorganisms invading plant tissues, endophytes produce extracellular hydrolyases as a resistance mechanism to overcome attack by the host against pathogenic invasion and/or to get nutrition from the host.

Such enzymes including pectinases, esterases, cellulases and lipases, (Petrini et. al. 1992) proteinase, (Reddy et al., 1996) $\alpha 1,4$-glvcan lyase (Nielsen et al., 2000) and phosphatases (Maccheroni and Azevedo, 1998) have been documented from different endophytes. In addition to above mentioned enzymes endophytes also produce laccase, two isolates of Fusarium proliferatum and $F$. proliferatum strains produce laccases during infection of wheat seedlings (Kwon and Anderson, 2001).

\section{Conclusion}

Endophytes are not only the interesting 
Class of microorganisms but may also play a significant role in their utilization in industry, agriculture, medicine, food, textiles, bioremediation, natural cycling as biofertilizers and many other ways. Microorganisms occupying virtually every living and non-living niche on earth have proven to be a very rewarding source of bioactive and structurally diverse natural products

It could be realized that plants may serve as a reservoir of unimaginable numbers of microorganisms known as endophytes which have typically gone unnoticed for centuries. Many more endophytes may produce unusual secondary metabolites of tremendous importance. In fact a comprehensive study has indicated that $51 \%$ of biologically active substances isolated from endophytic fungi were previously unknown. New pharmaceutical compounds, secondary metabolites, agents for biological control of insect-pests and plant diseases besides other useful characteristics could be found, by further exploration of endophytic microorganisms. This is a broad field of investigation that is almost entirely open to new findings. It is expected that new ways of interactions between endophytes and their hosts will be found. It is expected also that new drugs of biotechnological importance produced by endophytes will be described with the increasing knowledge focusing on these microorganisms. There is a need of world wide scientific effort to isolate endophytes and study their secondary metabolism.

\section{References}

Ballio, A., Bossa, F., DiGiogio, P., Ferranti, P., Paci, M., Pucci,. P., Scaloni, A., Segre, A., Strobel, G, A. 1994. Structure of the pseudomycins, new lipodepsipeptides produced by
Pseudomonas syringae MSU $16 \mathrm{H}$. FEMS Lett., 355: 96-100.

Bashyal, B., Li, J.Y., Strobel, G.A., Hess, W.M. 1999. Seimatoantlerium nepalense, an endophytic taxol producing coclomycete from Himalayan yew (Taxus wallichiana), Mycotaxon., 72: 33-42.

Bhagobaty, R.K., Joshi, S.R. 2009. Promotion of seed germination of green gram and chick pea by Penicillium verruculosum RS7PF, a root endophytic fungus of Potentilla fulgens L. Adv. Biotechnol., 8: 7-15.

Bhagobaty, R.K., Joshi, S.R. 2011. Metabolite profiling of endophytic fungal isolates of five ethnopharmacologically important plants of Meghalaya, India. J. Metabolomics Syst. Biol., 2: 20-31.

Borel, J.F., Kis, Z.L. 1991. The discovery and development of cyclosporine. Transplant. Proc., 23(2): 1867-1874.

Brady, S.F., Clardy, J. 2000. CR377, a new pentaketide antifungal agent isolated from an endophytic fungus. J. Nat. Prod., 63: 1447-1448.

Burke, R.M., Cairney, J.W.G. 1997. Purification and characterization of a p-14-endoxylanase from the ericoid mycorrhizal fungus Hymenoscyphus ericae. New Phytol., 135: 345-352.

Burres, N.S., Premachandran, U., Humphrey, P.E., Jackson, M., Chen, R.H. 1992. A new immunosuppressive Cytochalasin isolated from a Pestalotia sp. J. Antibiotics, 45: 13671369.

Castillo, U.F., Harper, J.K., Strobel, G.A., Sears, J., Alesi, K., Ford, E., Lin, J., Hunter, M., Maranta, M., Fe, H., Yaver, D., Jensen, J.B., Porter, H., Robison, R., Millar, D., Hess, W, M., Condron, M., Teplow, D. 2003. Kakadumycins, novel antibiotics from Streptomyces sp. NRRL 30566, an 
endophyte of Grevillea pteridifolia. FEMS Lett., 224: 183-190.

Castillo, U.F., Strobel, G.A., Ford, E.J., Hess, W.M., Porter, H., Jensen, J.B., Albert, H., Robison, R., Condron, M, A., Teplow, D, B., Stevens, D., Yaver, D. 2002. Munumbicins, widespectrum antibiotics produced by Streptomyces NRRL 30562, endophytic on Kennedia nigriscans. Microbiol., 148: 2675-2685.

Chaturvedi, P., Gajbhiye, S., Roy, S., Dudhale, R., Chowdhary, A. 2014. Determination of kaempferol in extracts of Fusarium chlamydosporum, an endophytic fungi of Tylophora indica (Asclepeadaceae) and its anti-microbial activity. $J$. Pharm. Biol. Sci., 9: 51-55.

Chithra, S., Jasim, B., Anisha, C., Mathew, J., Radhakrishnan, E.K. 2014a. LCMS/MS based identification of piperine production by endophytic Mycosphaerella sp. PF13 from Piper nigrum. Appl. Biochem. Biotechnol., 173: 30-35.

Chithra, S., Jasim, B., Sachidanandan, P., Jyothis, M., Radhakrishnan, E.K. 2014b. Piperine production by endophytic fungus Colletotrichum gloeosporioides isolated from Piper nigrum. Phytomedicine, 21: 534-540.

Colletotrichum sp., an endophytic fungus in Artemisia annua. Plant Sci., 151: 6773.

Colwell, R.R. 2002. Fulfilling the promise of biotechnology. Biotechnol. Adv., 20: $215-228$.

Cragg, G.M. 2002. Natural Product Drug Discovery and Development, The United States National cancer Institute Role. Puerto Rico Health Science Murnal, 21: 97-111.

Cragg, G.M., Newman, D.J. $2001 b$. Cytotoxic alkaloids from the marine sponge Thorectandra. J. Nat. Prod., 67: 232-244.

Cragg, G.M., Newman, D.J., 2001a. Natural Product Drug Discovery in the Next Millennium. Pharma. Biol., 39: S8-17.

Dai, C.C., Yu, B.Y., Li, X. 2008. Screening of endophytic fungi that promote the growth of Euphorbia pekinensis. Afr. J. Biotechnol., 7: 3505-3510.

Daisy, B., Runyon, J.B. 2002b. Naphthalene, an insect repellent, is produced by Muscodor vitigenus, a novel endophytic fungus. Microbiol., 148: 3737-3741.

Daisy, B., Strobel, G., Ezra, D., Castillo, U., Baird, G., Hess, W.M. 2002a. Muscodor vitigenus anam. Sp. Nov., an endophyte from Paullinia paullinioides. Mycotaxon. 84:3950.Daisy. B.H., Strobel.G.A., Castillo. U., Ezra. D., Sears. J., Weaver.

Demain, A.L. 2000. Microbial natural products: a past with a future, p. 3-16. In S. K. Wrigley, M. A. Hayes, R. Thomas, E. J. T. Chrystal, and N. Nicholson (ed.), Biodiversity: new leads for pharmaceutical and agrochemical industries. The Royal Society of Chemistry, Cambridge, United Kingdom.

Ek, M., Ljungquist, P.O., Stenström, E. 1983. Indole-3-acetic acid production by mycorrhizal fungi determined by gas chromatography-mass spectrometry. New Phytol., 94: 401407.

Findlay, J.A., Bothelezi, S., Li, G., Sevek, M. 1997. Insect toxins from an endophyte fungus from wintergreen $J$. Nat. Prod., 60:1214-1215.

Garyali, S., Reddy, M.S. 2013. Taxol production by an endophytic fungus, Fusarium redolens, isolated from Himalayan yew. J. Microbiol. Biotechnol. 23, 1372-1380.

Govindappa, M., Channabasava, R., 
Sowmya, D.V., Meenakshi, J., Shreevidya, M.R., Lavanya, A., Santoyo, G., Sadananda, T.S. 2011. Phytochemical screening, antimicrobial and in vitro antiinflammatory activity of endophytic extracts from Loranthus sp. Pharmacognosy J., 3, 82-90.

Guo, B., Dai, J., Ng, S., Huang, Y., Leong, C., Ong, W., Carte, B.K. 2000. Cytonic acids. A and B, novel tridepside inhibitors of hCMV protease from the endophytic fungus Cytonaema species. J. Nat. Prod. 63:602-604.

Hammerschmidt, L., Wray, V., Lin, W., Kamilova, E., Proksch, P., Aly, A.H. 2012. New styrylpyrones from the fungal endophyte Penicillium glabrum isolated from Punica granatum. Phytochem. Lett. 5, 600-603.

Harper, J, K., Ford, E, J., Strobel, G, A., Arif, A., Grant, D,M., Porco, J., Tomer, D.P., Oneill, K. 2003. Pestacin a 1, 3-dihydro isobenzofuran from Pestalotiopsis microspora possessing antioxidant and antimycotic activities. Tetrahedron. 59:2471-2476.

Harrison, L., Teplow, D., Rinaldi, M., Strobel, G, A. 1991. Pseudomycins, a family of novel peptides from Pseudomonas syringae, possessing broad spectrum antifungal activity. $J$. Gen. Microbiol., 137:2857-2865.

Horn, W, S., Simmonds, M, S, J., Schwartz, R, E., Blaney, W, M. 1995. Phomopsichalasin, a novel antimicrobial agent from an endophytic Phomopsis sp. Tetrahedron. 14:3969-3978.

Izumi, E., Ueda-Nakamura, T., Veiga V.F., Jr., Pinto, A.C., Nakamura, C.V. 2012. Terpenes from Copaifera demonstrated in vitro antiparasitic and synergic activity. J. Med. Chem. 55,
2994-3001.

Khan, A.L., Hamayun, M., Kang, S.M., Kim, Y.H., Jung, H.Y., Lee, J.H., Lee, I.J. 2012, Endophytic fungal association via gibberellins and indole acetic acid can improve plant growth under abiotic stress: An example of Paecilomyces formosus LHL10. BMC Microbiol. 12, 3.

Khan, A.L., Hussain, J., Al-Harrasi, A., AlRawahi, A., Lee, I.J. 2015. Endophytic fungi: Resource for gibberellins and crop abiotic stress resistance. Crit. Rev. Biotechnol. 35, $62-74$.

Kour. A., Abdul, S.S., Suriya. R., Phalisteen, $\quad$ S., $\quad$ Parvaiz, H.Q., Pankaj, S., Ravi, K.K and Vijeshwar, V. 2007. Isolation and identification of an endophytic strain of Fusarium oxysporum producing podophyllo toxin from Juniperus recurva World Journal of Microbiology and Biotechnology 24: 1115-1121.

Kudalkar, P., Strobel, G., Riyaz-Ul-Hassan, S., Geary, B., Sears, J. 2012. Muscodor sutura, a novel endophytic fungus with volatile antibiotic activities. Mycoscience 53, 319-325.

Kumar, S, S, D., Lau, C, S., Chan, W, K., Yang, D., Cheung, H, Y., Chen, F., Hyde, K, 2003. Immunomodulatory activity of an endophytic fungus from Tripterygium, wilfordii. Proceeding of the $2^{\text {nd }}$ International Conference on Medicinal Mushroom and the International Conference on Biodiversity and Bioactive Compounds, 367-373.

Kumar, S, S, D., Lau, C, S., Chan, W, K., Yang, D., Cheung, H, Y., Chen, F., Hyde, K, D., 2005. Immunomudulatory compounds from Pestalotiopsis leucothes an endophytic 
fungus from Tripterygium wilfordii. Life science 72(2): 147-156.

Kusari, S, Verma, V.C., Lamshoeft, M., Spiteller, M. 2014a. An endophytic fungus from Azadirachta indica A. Juss. that produces azadirachtin. World J. Microbiol. Biotechnol. 2012. 28, 1287-1294.

Kusari, S. Singh, S. Jayabaskaran, C.. 2014b. Rethinking production of Taxol® paclitaxel) usingendophyte biotechnology. Trends Biotechnol. 32, 304-311.

Kwon, S, L., Anderson, A, J. 2001, Laccase isozyme production by an opportunistic pathogen, a Fusarium proliferatum isolate from wheat. Physiol. Mol. Plant Pathol., 59: 235242.

Lee, J, C., Yang, X., Schwartz, M., Strobel, G., Clardy, J. 1995a. The relationship between an endangered North American tree and an endophytic fungus. Chem. Biol. 2:721-727.

Lee, J., Lobkovsky,E., Pliam, N, B., Strobel, G, A., Clardy, J. 1995b. Subglutinols $\mathrm{A}$ and B, immunosuppressive compounds from the endophytic fungus Fusarium subglutinans. J. Org. Chem. 60:7076-7077.

Li, C., Johnson, R, P., Porco, J, A. 2002. Total synthesis of the quinine epoxide dimmer (+)-torreyanic acid, application of a biomimetic oxidation/ electrocyclization/ Diels -Alder dimerzation cascade. J. Am. Chem. Soc. 125: 5059-5106.

Li, D., Chen, Y., Pan, Q., Tao, M., Zhang, W. 2014. A new eudesmane sesquiterpene from Nigrospora oryzae, an endophytic fungus of Aquilaria sinensis. Rec. Nat. Prod. 8, 330-333.

Li, J, Y., Harper, J, K., Grant, D, M., Tombe, B, O., Bashyal, B., Hess, W, M., Strobel, G, A. 2001b. Ambuic acid, a highly functionalized cyclohexenone with antifungal activity from Pestalotiopsis spp and Monochaetia spp. Phytochemistry. 56: 463-468.

Li, J, Y., Sidhu, R, S., Ford, E., Hess, W, M., Strobel, G, A. 1998. The induction of taxol production in the endophytic fungus Periconia sp. from Terreya grandifolia. J. Ind. Microbiol. 20: 259264.

Li, J, Y., Strobel, G, A. 2001a. Jesterone and hydroxy-jesterone antioomycete cyclohexenone epixides from the endophytic fungus Pestalotipsis jesteri. Phytochemistry 57: 261-265.

Li, J, Y., Strobel, G, A., Harper, J, K., Lobkovsky, E., Clardy. J. 2000. Cryptocin, a potent tetramic acid, antimycotic from the endophytic fungus Cryptosporiopsis cf. quercina. Org. Lett. 2:767-770.

Li, J, Y., Strobel, G, A., Sidhu, R., Hess, W, M., Ford, E. 1996. Endophytic taxol producing fungi from Bald Cypress Taxodium distichum, Microbiology. 142:2223-22226.

Lu, H., Zou, W.X., Meng, J.C., Hu, J., Tan, R.X. 2000. New bioactive metabolites produced.

Luo, J., Liu, X., Li, E., Guo, L., Che, Y. 2013. Arundinols A-C and arundinones A and B from the plant endophytic fungus Microsphaeropsis arundinis. J. Nat. Prod. 76, 107-112.

Maccheroni, W., Azevedo, J, L. 1998. Synthesis and secretion of phosphatases by endophytic isolates of Colletotrichum musae grown under conditions of nutritional starvation. $J$. Gen. Appl. Microbiol. 44: 381.

Manabu, S., Takebayashi, M., Katsuichi, S., Michiko, T., Atsushi, Y., Fusao, T. 2002. Endophytes as producers of xylanase. Journal of Bioscience and Bioengmeering. 93(1): 88-90.

Manici, L.M., Kelderer, M., Caputo, F., 
Mazzola, M. 2015. Auxin-mediated relationships between apple plants and root inhabiting fungi: Impact on root pathogens and potentialities of growthpromoting populations. Plant Pathol. 64, 843-851.

Meshram, V., Kapoor, N., Saxena, S. 2013. Muscodor kashayum sp. nov.-A new volatile anti-microbial producing endophytic fungus. Mycology 4, 196204.

Miller, J, D., Laflamme, A, M., Sobol, Y., Lafontaion, P., Greenhalgh, R. 1998. Fungi and fungal products in some Canadian houses. Int. Biodeterior. 24:103-120.

Newman. D.J., Cragg. G.M., and Snader. K.M., 2003. Natural Products as Source of New Drugs over the Period 1981-2002. J. Nat. Prod. 66: 10221037.

Nielsen, J, E., Yu, S, K., Bojko, M.., Marcussen, J. 2000. A-1, 4- Glecan lyase-producing endophyte of Gracilariopsis spp (Rhodophyta) from China. Eur. J. Phycol. 35:207-212.

Petrini, O., Sieber, T, H., Toti, L., Viret, O, 1992. Ecology, metabolite production and substrate utilization in endophytic fungi-Natural Toxins. 1: 185-196.

Porter, J, R., Folsom, P, A., Eyberger, A, L. 2004. (Newark, DE). Endophytes for production of podophyllotoxin. US patent 20040248265.

Pu, X., Qu, X.; Chen, F., Bao, J., Zhang, G., Luo, Y. 2013. Camptothecinproducing endophytic fungus Trichoderma atroviride LY357: Isolation, identification, and fermentation conditions optimization for camptothecin production. Appl. Microbiol. Biotechnol. 97, 9365-9375.

Pulici, M., Sugawara, F., Koshino, H., Okada, G., Esumi, Y., Uzava, J., Yoshida, S. 1997. Metabolites of Pestolotiopsis spp endophytic fungus of Taxus brevifolia. Phytochemistry 46: 313-319.

Pulici, M., Sugawara, F., Koshino, H., Uzawa, J., Yoshida, S., Lobkovsky, E., Clardy, J., 1996a. Pestalotiopsin-A and pestalotiopsin-B, new caryophyllenes from an endophytic fungus of Taxus brevifolia. J. Org. Chem. 61: 21222124.

Pulici, M., Sugawara, F., Koshino, H., Uzawa, J., Yoshida, S., Lobkovsky, E., Clardy, J. 1996b. A new isodiminol from Pestalotiopsis sp. J. Nat. Prod. 59: 47-48.

Puri, S, C., Nazir, A., Chawla, R., Arora, R., Riyaz-ul-Hasan., Amina, T., Ahmed, B., Verma, V., Singh, S., Sagar, R., Sharma, A., Kumar, R., Sharma, R, K. Qazi, G, N. 2005a. The endophytic fungus Trametes hirsuta as a novel alternative source of podophyllotoxin and related aryl tetralin lignans, Journal of Biotechnology.

Puri, S, C., Verma, V., Amna, T., Qazi, G, N., Spiteller, M. 2005b. An Endophytic fungus from Nothapodytes foetida that Produce Camptothecin. J. Nat. Prod. 68(12): 1717-1719.

Qiang, X., Weiss, M., Kogel, K.H., Schäfer, P. 2012. Piriformospora indica-A mutualistic basidiomycete with an exceptionally large plant host range. Mol. Plant Pathol. 13, 508-518.

Reddy, P, V., Lam, C, K., Belanger, F, C. 1996. Mutualistic fungal endophytes express a proteinase that is homologous to proteases suspected to be important in fungal pathogenicity. Plant Physiol., 111: 1209-1218.

Rehman, S., Shawl, A., S., Kour, A., Andrabi, R., Sultan, P., Sudan, P and Qazi, G, N. 2008. An Endophytic Neurospora sp. from Nothapodytes foetida_ producing Camptothecin. Applied Biochemistry and Microbiology, 44(2). 203-209. 
Schiff, P, B., Horowitz, S, B. 1980. Taxol stabilizes microtubules in mouse fibroblast cells. Proc-Natl. Acad. Sci. USA 77: 1561-1565.

Selim K,A,1., El-Beih, A.A.1., AbdElRahman T.M., El-Diwany A.I. 2012. Biology of endophytic fungi. Curr. Res. Environ. Appl. Mycol., 2 (1) 3182.

Sirrenberg, A., Göbel, C., Grond, S., Czempinski, N., Ratzinger, A., Karlovsky, P., Santos, P., Feussner, I., Pawlowski, K. 2007. Piriformospora indica affects plant growth by auxin production. Physiol. Plant. 131, 581589.

Soca-Chafre, G. Rivera-Orduña, F.N. Hidalgo-Lara, M.E. HernandezRodriguez, C. Marsch, R. FloresCotera, L.B. 2011. Molecular phylogeny and paclitaxel screening of fungal endophytes from Taxus globosa. Fungal Biol. 115, 143-156.

Stierle, A., Strobel, G, A., Stierle, D. 1993. Taxol and taxane production by Taxomyces andreanae, an endophytic fungus of pacific yew. Science 260:.214-216.

Stinson, M., Ezra, D., Strobel. G. 2003. An endophytic Gliocladium sp. of Eucryphia cordifolia producing selective volatile antimicrobial compounds. Plant Sci. 165:913-922.

Strobel, G, A. 2002a. Microbial gifts from rain forests. Can. J.Plant Pathol. 24: $14-20$

Strobel, G, A., Ford, E., Worapong, J., Harper, J, K., Arif, A, M., Grant, D.M., Fung, P, C, W., Chan, K. 2002b. Ispoestacin, an isobenzofuranone from Pestalotiopsis microspore, possessing antifungal and antioxidant activities. Phytochemistry. 60: 179-183.

Strobel, G, A., Stierle, A., Stierle, D., Hess, W, M. 1993. Taxomyees andreanae a proposed new taxon for a bulbilliferous hyphomyeete associated with Pacific yew. Mycotaxon. 47: 7178.

Strobel, G, A.1997. Rainforest endophytes and bioactive products. Crit. Rev. Biotechnol. 22:315-333.

Suffness, M. 1995. Taxol. Science and applications CRC Press, Boca Raton. Fla.

Sun, Y., Xun, K., Wang, Y., Chen, X. 2009. A systematic review of the anticancer properties of berberine, a natural product from Chinese herbs. AntiCancer Drugs 20, 757-769.

Tacchowisan, T., Lu, C., Shen, Y., Lumyong, S. 2005. Secondary metabolites from endophytic Streptomyces aureofaciens and their antifungal activity. Microbiology. 151: 1691-1695.

Tan, R, X., Zou, W, X. 2001. Endophytes; a rich source of functional metabolites Nat. Prod. Rep. 18: 448-459.

Teles, H, L., Silva, G, H., Castro, G., Mida, S., Pereira, J, O., Costa, C, M. Haddad, R., Eberilu, M, N., and Young, M, C, M., Aranjo, A, R. 2005. Benzopyrans from Curvularia spp an endophytic fungus associated with Ocotea corymbosa (Lauraccae). Phytochemistry 66(18): 2363-2367.

Umashankar, T., Govindappa, M., Ramachandra, Y, L. 2014. In vitro antioxidant and antimicrobial activity of partially purified coumarins from fungal endophytes of Crotalaria pallida. Int. J. Curr. Microbiol. Appl. Sci. 3, 58-72.

Verma, V.C., Lobkovsky, E., Gange, A.C., Singh, S.K., Prakash, S. 2011. Piperine production by endophytic fungus Periconia sp. isolated from Piper longum L. J. Antibiot. 64, 427431.

Vinodhini, D., Agastian, P. 2013, Berberine 
production by endophytic fungus Fusarium solani from Coscinium fenestratum. Int. J. Biol. Pharm. Res. 4, 1239-1245.

Wagenaar, M., Corwin, J., Strobel, G, A., Clardy, J. 2000. Three new Cytochalasins produced by an endophytic fungus in the genus Rhanocladiella. J. Nat. Prod. 63: 1692-1695.

Walsh, T, A. 1992. Inhibitors of B-glucan synthesisIn J.A. Sutcliffe and N. H. Georgopapadakou (ed.). Emerging targets in antibacterial and antifungal chemotherapy. Chapman and Hall, London, United Kingdom. 349-373.

Wang, J., Li, G., Lu, H., Zheng, Z., Huang, Y., Su, W. 2000. Taxol from Tubercularia sp. Strain TF5, an endophytic fungus of Taxus matrel. FEMS Microbiol. Lett. 193: 249-253.

Waqas, M., Khan, A.L., Kamran, M., Hamayun, M., Kang, S.M., Kim, Y.H., Lee, I.J. 2012. Endophytic fungi produce gibberellins and indoleacetic acid and promotes host-plant growth during stress. Molecules 17, 10754 10773.

Waqas, M., Khan, A.L., Kang, S.M., Kim, Y.H., Lee, I.J. 2014. Phytohormoneproducing fungal endophytes and hardwood-derived biochar interact to ameliorate heavy metal stress in soybeans. Biol. Fertil. Soils, 50, 11551167.
Worapong, J., Strobel, G, A., Daisy, B., Castillo, U., Baird, G., Hess, W, M. 2002. Muscodor roseaus an endophyte from Grevillea pteridifolia. Mycotaxon. 81: 463-475.

Xiong, Z,Q., Yang, Y,Y., Zhao, N., Wang, Y. 2013. Diversity of endophytic fungi and screening of fungal paclitaxel producer from Anglojap yew, Taxus $x$ media. BMC Microbiol. 13, 71.

Zaher, A.M., Moharram, A.M., Davis, R., Panizzi, P., Makboul, M.A., Calderón, A.I. 2015. Characterisation of the metabolites of an antibacterial endophyte Botryodiplodia theobromae Pat. of Dracaena draco L. by LCMS/MS. Nat. Prod. Res. 29, doi:10.1080/14786419.2015.1012715.

Zhang, B., Salituro, G., Szalkowaki, D., Li, Z., Zhang, Y., Royo, I., Vilella, D., Dez, M., Pelacz, F., Ruby, C., Kendali, R, L., Mao, X., Griffin, P., Calaycay, J., Zieruth, J, R., Heck, J, V., Smith, R, G., Moller, D, E. 1999. Discovery of small molecule insulin mimetic with antidiabetic activity in mice. Sci., 284: 974-981.

Zhang, Y.Z., Sun, X., Zechner, D., Sachs, B., Current, W., Gidda, J., Rodriguez, M., Chen, S, H. 2001. Synthesis and antifungal activities of novel 3-amido bearing pseudomycin analogs. Bioorg. Med.Chem., 11: 903-907.

\section{How to cite this article:}

Suriya Rehman. 2016. Endophytes: The Producers of Important Functional Metabolites. Int.J.Curr.Microbiol.App.Sci. 5(5): 377-391. doi: http://dx.doi.org/10.20546/ijcmas.2016.505.039 